\title{
Variations within and amongst normal men of movement characteristics of seminal spermatozoa
}

\author{
D. F. Katz, J. W. Overstreet* and F. W. Hanson \\ Departments of Obstetrics and Gynecology and *Human Anatomy, School of Medicine, \\ University of California, Davis, California 95616, U.S.A.
}

\begin{abstract}
Summary. Movement characteristics of the seminal spermatozoa of 9 men of contemporary fertility were studied using time-exposure photomicrography. Five different ejaculates, collected over a 9-month period, were analysed for each man. The assessment of sperm motility focussed on classical parameters (\% motile spermatozoa and the total swimming speed, considering all motile spermatozoa) as well as several newly defined movement characteristics (\% progressive spermatozoa, progressive swimming speed, and \% straight-swimming, rolling and yawing spermatozoa). These new measures distinguished weakly motile from vigorously motile spermatozoa, and also assessed geometrical attributes of the swimming trajectories of the vigorous spermatozoa. The \% motility and the total and progressive swimming speeds did not differ significantly amongst the fertile men. The percentage of progressive spermatozoa differed significantly among the 9 men, but this was due to the outlying values of a single donor. Significant differences among men did occur in the percentages of straight-swimming, rolling and yawing spermatozoa. In addition, considerable variability was found among the different ejaculates of individual men.
\end{abstract}

\section{Introduction}

The movements of spermatozoa are a direct expression of a number of intracellular mechanisms associated with the processes of maturation, transport, capacitation and fertilization (Katz \& Overstreet, 1980). Attention to sperm motility is, therefore, germane to studies of the basic biology of spermatozoa, as well as to the clinical assessment of male fertility. In this regard, the movement of spermatozoa as they swim in human semen offers the potential of providing a great deal of information about testicular and epididymal function as well as the secretions of the male accessory glands. However, the information on sperm movement in human semen assembled to date is difficult to integrate and interpret, because there has been no standard, objective method for sperm motility assessment. Most investigators have assessed visually the percentage of motile spermatozoa and have ranked subjectively the 'quality' of motility (Eliasson, 1975). While the former can at least be defined unambiguously, the latter has variously been described as reflecting, for example, the 'vigour' and/or 'progressiveness' of the movement. In principle, the emphasis on these two types of measures of sperm movement seems sound. One measures the fraction of spermatozoa exhibiting any evidence of active flagellar contractility, while the other assesses the swimming performance of those active cells. Unfortunately, the subjective nature of visual assessment so limits the accuracy and precision of the results that only the most obvious differences between sperm suspensions can be detected (Katz \& Overstreet, 1979). Moveover, subjective visual methods virtually preclude the study of distinctions in the motility of different spermatozoa within a suspension.

In most studies of human sperm movement, only a single semen specimen from each man 
has been analysed. Earlier work has indicated, however, that there can be substantial variability among different ejaculates of individual men (Freund, 1962; Schwartz, Laplanche, Jouannet \& David, 1979). Therefore the accuracy with which a single semen specimen reflects an individual's testicular and/or epididymal function remains uncertain. This question is of particular relevance when comparisons among men are important, as in the assessment of human infertility. Indeed, the reliability of the clinical diagnosis of human male fertility is complicated both by methodological subjectivity and the uniqueness of each ejaculate. Neither the distinguishing movement characteristics of a 'normal' spermatozoon, nor even the most general standards for sperm motility in fertile human semen have yet been established. The studies described herein were undertaken to begin to answer these questions.

\section{Materials and Methods}

Semen specimens were obtained by masturbation from 9 donors in our therapeutic artificial insemination programme. These men were medical students between the ages of 21 and 28 years and all produced at least 1 pregnancy during the period of study. Five different specimens were studied at random times over a 9-month period. Each semen specimen was obtained after 2-7 days of prior sexual abstinence. All measurements were performed within $1 \mathrm{~h}$ of collection, allowing sufficient time for semen reliquefication.

Movement characteristics of the spermatozoa were assessed by taking 1-sec time-exposure photomicrographs of whole semen under dark-field illumination at a magnification of $\times 200$. The semen $(10 \mu \mathrm{l})$ was examined on a glass slide under a coverglass (No. $1 \frac{1}{2}, 22 \times 22 \mathrm{~mm}$ ). These suspensions were approximately $20 \mu \mathrm{m}$ deep and allowed the spermatozoa to swim freely. Semen samples were maintained at room temperature before slide preparation but were photographed at $37^{\circ} \mathrm{C}$ using an air curtain incubator (Sage Instruments).

For each sample, a single slide was prepared on which 7 independent microscopic fields were photographed. Processed films were projected as a negative strip and analysed on an analysis console (Overstreet, Katz, Hanson \& Fonseca, 1979). Seven different sperm movement characteristics were measured. (1) Spermatozoa exhibiting any evidence of active flagellar movement were classified as motile and, based on a random sample of 50 spermatozoa, distributed uniformly among the 7 fields, a percentage of motile spermatozoa was determined. (2) The mean 'swimming speed' of the motile sperm populations as a whole was determined from the 'track' lengths on the time-exposed negatives. This speed, representative of all motile spermatozoa, is referred to as the 'mean total swimming speed'. It was based on a random sample of 15 motile spermatozoa, which were distributed uniformly among all 7 fields. (3) The percentage of progressive spermatozoa was defined as the fraction of these 15 motile spermatozoa swimming at a rate of $25 \mu \mathrm{m} / \mathrm{sec}$ or greater. Swimming speeds of additional progressive spermatozoa were measured to achieve a sample size of 15 , and (4) the 'mean progressive swimming speed' of this subpopulation was computed. Three additional movement characteristics were determined from the time-exposed negative. These focussed on geometrical attributes of the trajectories of the progressive spermatozoa only. (5) A percentage of 'straight-swimming' spermatozoa indicated the size of the sperm population with trajectories of no measurable curvature. (6) A percentage of 'rolling' spermatozoa focussed upon those spermatozoa regularly rotating the sperm head completely about its longitudinal axis. (7) Finally, a percentage of 'yawing' spermatozoa was determined from those cells undergoing periodic lateral excursions of the head about the axis of propulsion. The details of these definitions and the methods of measurement have been published previously (Overstreet et al., 1979).

The objective of the data analysis was to investigate variability in sperm movement characteristics in different ejaculates of individual men, as well as differences amongst the group of men. The total and progressive swimming speeds are measures sampled on a per-sperm basis, and therefore take into account the variations within individual sperm suspensions. Thus variability both within and amongst men as a group can be simultaneously assessed for these 
speeds. In the present study, differences in sperm movement in different fields of the same microscopic slide preparation were not analysed. Rather, these differences were taken as random, and data were pooled from the different fields on each slide. For the total and progressive swimming speeds nested one-way analyses of variance were performed, with donors and ejaculates-within-donors taken as random effects. Because there was no significant variation of the speeds in both main effects, we also studied the variability among ejaculates within individual donors, using one-way analysis of variance. The percentages of motile, progressive, straight-swimming, rolling and yawing spermatozoa are bulk parameters that provided a single measure for each sperm suspension. Therefore variability among men overall was compared directly to variability within men by one-way analyses of variance. Individual values of these percentages were transformed to angles before analysis. The differences of these percentages within individual men were assessed by treating them as counts in $2 \times 5$ contingency tables and performing $\chi^{2}$ analyses (Snedecor \& Cochran, 1974).

\section{Results}

The measurements of total swimming speed, progressive swimming speed, the percentage of motile spermatozoa, and the percentage of progressive spermatozoa are summarized in Table 1. Neither of the speeds nor the percentage motility varied significantly amongst men. Although the percentage of progressive spermatozoa did vary significantly, this appeared due to the relatively low values for Donor 9. Re-analysis of the data, excluding this donor, resulted in a lack of significant variability in percentage of progressive spermatozoa among the remaining $8 \mathrm{men}$. The values of total and progressive swimming speed did not vary significantly within the men, when considered as a group and assessed by the nested analysis of variance. When the 5 semen samples were compared for each man individually, 5 men had significant variation from ejaculate to ejaculate in the total swimming speed, and 8 men exhibited significant variation in the progressive swimming speed (Table 2). Percentage motility varied significantly among the 5 ejaculates of $8 \mathrm{men}$, and the percentage of progressive spermatozoa did so in $3 \mathrm{men}$. The measurements of the geometrical attributes of the swimming trajectories of the progressive spermatozoa are summarized in Table 3. The percentages of straight-swimming, rolling, and yawing spermatozoa all varied significantly among the different men. The percentage of straight-swimming spermatozoa differed significantly among the ejaculates of 1 man, while the percentage of rolling spermatozoa differed significantly in 5 men. The percentage of yawing spermatozoa did not differ significantly within any individual man.

Table 1. Values (mean \pm s.e.m.) of the percentages of motile spermatozoa, percentages of progressive spermatozoa (i.e. swimming at a rate $\geqslant 25 \mu \mathrm{m} / \mathrm{sec}$ ), total swimming speed (based on all motile spermatozoa), and progressive swimming speed (based on progressive spermatozoa only) for 5 semen samples per man

\begin{tabular}{|c|c|c|c|c|c|c|c|c|c|c|}
\hline & \multicolumn{9}{|c|}{ Donor } & \multirow[b]{2}{*}{ Cumulative } \\
\hline & 1 & 2 & 3 & 4 & 5 & 6 & 7 & 8 & 9 & \\
\hline 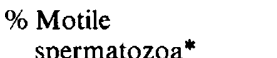 & $\begin{array}{l}89 \\
+4\end{array}$ & $\begin{array}{l}85 \\
+4\end{array}$ & $\begin{array}{l}82 \\
+6\end{array}$ & $\begin{array}{l}76 \\
+5\end{array}$ & $\begin{array}{l}81 \\
+8\end{array}$ & $\begin{array}{l}87 \\
+2\end{array}$ & $\begin{array}{l}82 \\
+6\end{array}$ & $\begin{array}{l}81 \\
+6\end{array}$ & $\begin{array}{l}63 \\
+8\end{array}$ & $\begin{array}{l}81 \\
+2\end{array}$ \\
\hline Total swimming & $\overline{35}$ & $\overline{44}$ & $\overline{34}$ & 37 & 25 & 42 & 35 & 33 & 22 & 34 \\
\hline speed $^{*} \dagger(\mu \mathrm{m} / \mathrm{sec})$ & \pm 2 & \pm 3 & \pm 3 & \pm 2 & \pm 2 & \pm 2 & \pm 2 & \pm 2 & \pm 3 & \pm 2 \\
\hline $\begin{array}{l}\text { \% Progressive } \\
\text { spermatozoa }\end{array}$ & $\begin{array}{l}73 \\
+6\end{array}$ & $\begin{array}{l}80 \\
+7\end{array}$ & $\begin{array}{l}64 \\
+10\end{array}$ & $\begin{array}{l}78 \\
+6\end{array}$ & $\begin{array}{l}61 \\
+8\end{array}$ & $\begin{array}{l}85 \\
+6\end{array}$ & $\begin{array}{l}68 \\
+5\end{array}$ & 66 & $\begin{array}{l}45 \\
+9\end{array}$ & $\begin{array}{l}69 \\
+3\end{array}$ \\
\hline Progressive swimming & $\overline{45}$ & $\overline{52}$ & 49 & 42 & 38 & 47 & 44 & 41 & $\frac{1}{46}$ & 45 \\
\hline speed $^{* \dagger}(\mu \mathrm{m} / \mathrm{sec})$ & \pm 2 & \pm 2 & \pm 2 & \pm 1 & \pm 1 & \pm 2 & \pm 1 & \pm 2 & \pm 1 & \pm 1 \\
\hline
\end{tabular}

* Values do not differ significantly among men.

$\dagger$ Values do not differ significantly within men.

$\ddagger$ Values differ significantly among men $(0.01<P<0.05)$. Excluding Donor 9 as an outlier, values do not differ significantly among men. 
Table 2. Summary of the analyses of the variability of sperm movement characteristics amongst ejaculates within individual men

\begin{tabular}{|c|c|c|c|c|c|c|c|c|c|}
\hline \multirow{2}{*}{$\begin{array}{c}\text { Movement } \\
\text { characteristics }\end{array}$} & \multicolumn{9}{|c|}{ Donor } \\
\hline & 1 & 2 & 3 & 4 & 5 & 6 & 7 & 8 & 9 \\
\hline$\%$ Motile spermatozoa & ** & ** & ** & $* *$ & **** & N.S. & ** & ** & ** \\
\hline Total swimming speed & N.S. & $* * *$ & ** & **** & N.S. & ** & N.S. & **** & N.S. \\
\hline $\begin{array}{l}\text { \% Progressive } \\
\text { spermatozoa }\end{array}$ & N.S. & N.S. & * & N.S. & N.S. & N.S. & N.S. & ** & * \\
\hline $\begin{array}{l}\text { Progressive swimming } \\
\text { speed }\end{array}$ & ** & ** & $* *$ & $* * *$ & $* *$ & $* * *$ & ** & $* *$ & N.S. \\
\hline $\begin{array}{l}\text { \% Straight-swimming } \\
\text { spermatozoa }\end{array}$ & N.S. & N.S. & ** & N.S. & N.S. & N.S. & N.S. & N.S. & N.S. \\
\hline$\%$ Rolling spermatozoa & N.S. & N.S. & N.S. & ** & * & * & N.S. & * & * \\
\hline$\%$ Yawing spermatozoa & N.S. & N.S. & N.S. & N.S. & N.S. & N.S. & N.S. & N.S. & N.S. \\
\hline
\end{tabular}

N.S., not significantly different.

* Significantly different $(0.01<P<0.05)$.

** Significantly different $(0.001<P<0.01)$.

*** Significantly different $(P<0.001)$.

Table 3. Values (mean \pm s.e.m.) of the percentages of straight-swimming, rolling and yawing spermatozoa (for definitions see text) in 5 semen samples per man

\begin{tabular}{lllccccccccc}
\hline \multirow{2}{*}{$\begin{array}{c}\text { \% of } \\
\text { spermatozoa }\end{array}$} & \multicolumn{10}{c}{ Donor } & \\
\cline { 2 - 8 } & \multicolumn{1}{c}{2} & \multicolumn{1}{c}{3} & \multicolumn{1}{c}{4} & \multicolumn{1}{c}{5} & \multicolumn{1}{c}{6} & 7 & 8 & 9 & Cumulative \\
\hline Straight swimming* & 44 & 60 & 50 & 62 & 84 & 63 & 52 & 29 & 64 & 56 \\
& \pm 8 & \pm 5 & \pm 11 & \pm 7 & \pm 4 & \pm 7 & \pm 8 & \pm 5 & \pm 7 & \pm 3 \\
Rolling† & 49 & 59 & 59 & 68 & 75 & 63 & 67 & 37 & 79 & 62 \\
Yawing* & \pm 6 & \pm 7 & \pm 3 & \pm 10 & \pm 8 & \pm 10 & \pm 7 & \pm 9 & \pm 8 & \pm 3 \\
& 41 & 24 & 35 & 29 & 6 & 31 & 24 & 45 & 23 & 29 \\
& \pm 7 & \pm 3 & \pm 5 & \pm 7 & \pm 3 & \pm 6 & \pm 3 & \pm 7 & \pm 5 & \pm 2 \\
\hline
\end{tabular}

* Values differ significantly among men, $P<0.001$.

$\dagger$ Values differ significantly among men, $0.01<P<0.005$.

It is possible to consider the relation between some of the movement characteristics that we measured by means of the following qualitative arguments. If TS = mean total swimming speed; PS = mean progressive swimming speed; NS = mean swimming speed of the non-progressive spermatozoa; and $\% \mathrm{P}=$ percentage of progressive swimming spermatozoa, the following equation, applicable to each sperm suspension, can be analytically derived (see Appendix):

$$
\begin{aligned}
\mathrm{TS}= & \left(\frac{1}{100}\right)[(\% \mathrm{P}) \mathrm{PS}+(1-\% \mathrm{P}) \mathrm{NS}] \\
& \left(\frac{1}{100}\right)[(\% \mathrm{P})(\mathrm{PS}-\mathrm{NS})+\mathrm{NS}]
\end{aligned}
$$

A statistical analysis of experimental data to verify this multivariate relationship is complex, and was not undertaken in the present study. However, descriptive interpretation of our data clearly suggests that a positive correlation between TS and \%P exists (Text-fig. 1). Consequently, reference to Equation (1) is helpful in appreciating that the value of TS, the 'classical' parameter of sperm swimming does depend simultaneously upon the values of PS and $\% \mathrm{P}$, which were measured here, as well as the value of NS.

\section{Discussion}

Our approach to characterization of the motility of a sperm suspension involved a perspective that was more diversified than those reported previously. First, it questioned whether the 


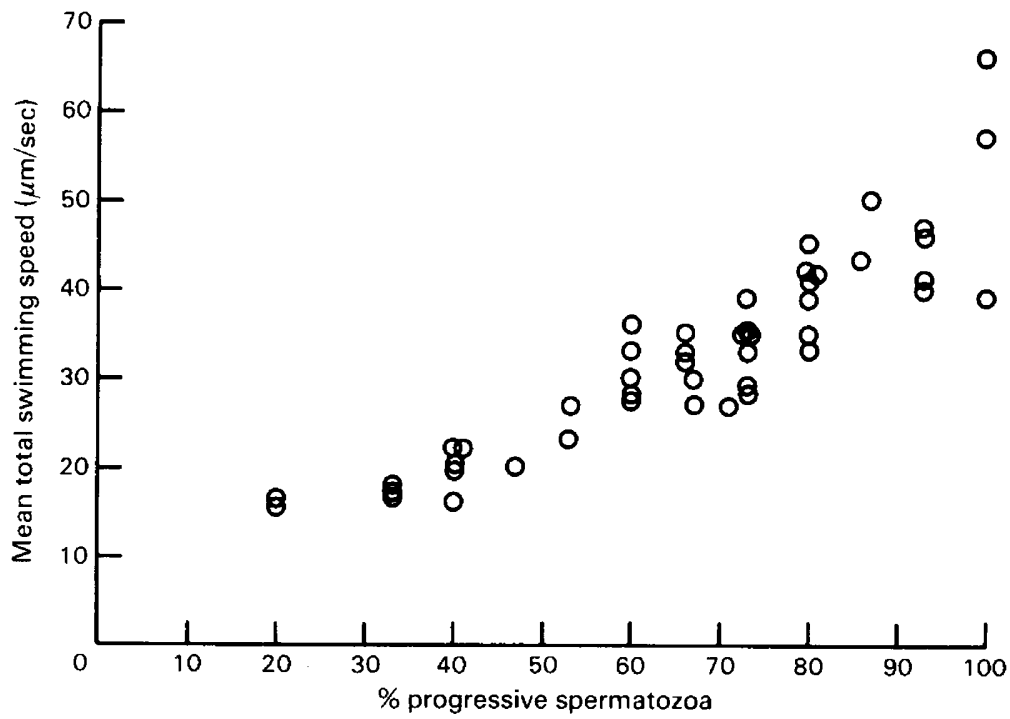

Text-fig. 1. Plot of pooled data on mean total swimming speed per ejaculate against percentage of progressive spermatozoa for 5 ejaculates from each of 9 fertile men.

spermatozoa were motile or not (i.e. percentage motility), and it assessed the movement of those motile spermatozoa as a whole in terms of their mean time-average rate of swimming (total swimming speed). This type of motility characterization is an objective expression of the 'quality' of sperm motility as evaluated in contemporary subjective assays. In addition, our approach focussed in greater detail on motile spermatozoa. Using swimming speed as the criterion, we subdivided these spermatozoa into two populations, those with 'weak' and 'strong' flagellar activity. The relative sizes of these two sperm subpopulations were determined (i.e. percentage progressive), as was the mean time-average rate of swimming of the stronger spermatozoa (progressive swimming speed). Finally we focussed exclusively on the progressive spermatozoa, assessing some of the geometrical attributes of their swimming trajectories (\% straight swimming, \% yawing, \% rolling).

In interpreting our results with respect to those of previous investigations, two types of comparisons are of interest. The absolute value of total swimming speed represents the random sampling of all motile spermatozoa within a suspension, and is the parameter measured in previous studies. The values of total swimming speed obtained here are comparable with those reported previously from objective measurement of the semen of fertile men (Makler, Itskovitz, Brandes \& Paldi, 1979; Overstreet et al., 1979), or semen of unknown fertility but 'good quality' (Harvey, 1960; Janick \& MacLeod, 1970). The bulk mean value of percentage motility obtained here $(81 \%)$ is slightly higher than that $(70 \%)$ in our earlier work (Overstreet et al., 1979), and substantially higher than the $45 \%$ obtained photomicrographically by Makler et al. (1979). In interpreting this latter discrepancy, it should be appreciated that our study included men selected for high semen quality and contemporary fertility. In contrast, the study of Makler et al. (1979) considered a group of relatively unselected men classified as fertile within the previous 4 years: it is possible that some members of this group would not have met the strict criteria for semen quality and recent fertility imposed in our study. Subjective visual studies of the percentage of motile spermatozoa in variously defined groups of 'fertile' men have yielded mean values in the range of 58-77\% (MacLeod \& Gold, 1951; Santomauro, Sciarra \& Varma, 1972; Nelson \& Bunge, 1974; Rehan \& Sobrero, 1975; Sobrero \& Rehan, 1975). However, caution must be exercised in referring to these values because of the large uncertainty $(20-30 \%)$ inherent in visual estimates (van Duijn, van Voorst \& Freund, 1971). 
There is a paucity of previous work with which to compare our data on the variation in sperm motility between different ejaculates of the same men. Freund (1962) made a systematic investigation of this variability in a number of parameters of semen quality, using a population of young men of unproven fertility. Included in these measures were subjective estimates of percentage motility and the degree of forward progression, the latter being ranked on an integral scale of $0-10$ and corresponding, to some extent, to our mean total swimming speed. Freund (1962) found that both these bulk measures differed significantly amongst men, although he also emphasized what he regarded as the high degree of variability in repeated semen samples from the same donor. Objective measurements have been performed of the swimming speeds of bull spermatozoa in repeated semen samples diluted with artificial media (van Duijn, 1962). Comparison of the mean values of swimming speeds per ejaculate indicated that significant differences did not exist among bulls sampled under random environmental conditions. In this regard it is important to appreciate that there is no unique strategy for describing and statistically comparing the swimming speeds of spermatozoa in different suspensions. The preceding studies characterized sperm swimming speeds in each suspension in terms of a single 'bulk' parameter, the mean speed in the latter case. We have chosen to describe each suspension by a sample 'distribution' of swimming speeds, in order to account for per-sperm variability. Consequently, nested analysis of variance showed that significant differences did not exist in swimming speeds among the 9 men. We also re-analysed our data on swimming speeds, limiting our comparisons to only mean values per ejaculate. Here computations based on one-way analysis of variance indicated that significant differences did exist among men. This distinction between conclusions drawn from 'bulk' parameters and 'distributed' per-sperm measures should be considered as a warning regarding the design and interpretation of experiments involving human sperm motility. Indeed, some of the comparisons among donors which were based on 'bulk' parameters (\% of motile spermatozoa and \% of progressive spermatozoa, regarding Donor 9 as an outlier) did not indicate significant differences. Other comparisons (percentages of straight-swimming, rolling, and yawing spermatozoa) indicated that differences did exist.

The discrimination of fertile and infertile males on the basis of semen quality remains a desirable but elusive goal. It seems logical that such a distinction could be made in many cases by assessing sperm movement characteristics. If this is so, the parameters most likely to reveal such a difference may not, therefore, be the bulk parameters of semen quality, since in our study these were found to vary even among highly fertile donors. The data on sperm motility obtained by subjective assessment and automated instruments, e.g. spectrophotometry (Atherton, Radany \& Polakoski, 1978), image-analysing computers (Katz \& Dott, 1975), and laser-Doppler spectrometers (Jouannet, Volochine, Deguent, Serries \& David, 1977) are limited to this type of 'bulk' presentation. Moreover, such data do not discriminate between spermatozoa that are only weakly motile and those that are vigorously progressive. As demonstrated by Equation (1) the bulk total swimming speed, which is obtained in the automatic methods, depends upon the percentage of progressive spermatozoa, their mean swimming speed, and the mean speed of the non-progressive spermatozoa. These are all parameters that may be of value in the fundamental study of fertile and non-fertile semen. Only methods of measurement which sample movement on a per-sperm basis can take into account the extensive normal biological variation which we have demonstrated in this study. These are exclusively photomicrographic methods and include time-exposure photomicrography, videomicrography and cinemicrography (for further details see Katz \& Dott, 1975; Katz \& Overstreet, 1979). At present we believe that such methods offer the best chance of distinguishing the semen of fertile and infertile men.

It is not yet possible to delineate a specific set of movement characteristics which identify a particular spermatozoon as being normal or fertile. The swimming speed and trajectory of a sperm cell are the hydrodynamic consequences of the shape of the flagellar beat and the frequency of contractions. These in turn are controlled by physical and chemical reactions within the cell. The variability recorded here in the geometrical attribute parameters of sperm 
movement may reflect the dynamics of intracellular function. That is, the movement characteristics of normal spermatozoa may not be unique, but constantly changing. An alternative possibility is that the proportion of competent spermatozoa may vary from one given fertile ejaculate to another. It is known that many aspects of human sperm movement are more homogeneous in human cervical mucus than in semen. This relative homogeneity is undoubtedly due, in part, to the physically stabilizing effect of the mucous microstructure. It may also be the result of selective penetration of the mucus by a subpopulation of (normal?) spermatozoa. Our in-vitro studies of human sperm-cervical mucous interaction suggest that, during the first $30 \mathrm{~min}$ of contact, only $10-30 \%$ of the motile seminal spermatozoa which reach the mucous interface succeed in gaining entry (Katz, Overstreet \& Hanson, 1980). This interval is comparable to that in which the majority of human seminal spermatozoa enter cervical mucus in vivo (Tredway et al., 1975). The seminal movement characteristics of these penetrating spermatozoa have not been specifically studied, although their morphology is known to be relatively homogeneous in vivo (Fredricsson \& Bjork, 1977) and in vitro (Perry, Glezerman \& Insler, 1977). Such observations are consistent with the possibility that only a fraction of the motile spermatozoa in semen are capable of entering and penetrating the mucus. Careful studies of sperm approach and entry at the semen-mucous interface may reveal what movement characteristics are shared by this unique sperm population.

The support of NIH grant HD12971 (D.F.K.) and NIH Research Career Development Award HD00224 (J.W.O.) is acknowledged.

\section{References}

Atherton, R.W., Radany, E.W. \& Polakoski, K.L. (1978) Spectrophotometric quantitation of mammalian sperm motility. I. Human. Biol. Reprod. 18, $624-628$.

Drake, T.S., Tredway, D.R. \& Buchanan, G.C. (1979) A reassessment of the fractional postcoital test. Am.J. Obstet. Gynec. 133, 382-385.

Eliasson, R. (1975) Analysis of semen. In Progress In Infertility, pp. 691-713. Eds S. J. Behrman \& R. W. Kistner. Little Brown, Boston.

Fredricsson, B. \& Bjork, G. (1977) Morphology of postcoital spermatozoa in the cervical secretion and its clinical significance. Fert. Steril. 28, 841-848.

Freund, M. (1962) Interrelationships among the characteristics of human semen and factors affecting semen-specimen quality. J. Reprod. Fert. 4, 143-159.

Harvey, C. (1960) The speed of human spermatozoa and the effect on it of various dilutents, with some preliminary observations on clinical material. $J$. Reprod. Fert. 1, 84-95.

Janick, J. \& MacLeod, J. (1970) The measurement of human spermatozoan motility. Fert. Steril. 21, 140-146.

Jouannet, P., Volochine, B., Deguent, P., Serres, C. \& David, G. (1977) Light scattering determination of various characteristic parameters of spermatozoa motility in a serie of human sperm. Andrologia 9 , 36-49.

Katz, D.F. \& Dott, H.M. (1975) Methods of measuring swimming speed of spermatozoa. J. Reprod. Fert. 45, 263-272.

Katz, D.F. \& Overstreet, J.W. (1979) Biophysical aspects of human sperm movement. In The Spermatozoon, pp. 413-420. Eds D. W. Fawcett \& J. M. Bedford. Urban \& Schwarzenberg, Inc., Baltimore.
Katz, D.F. \& Overstreet, J.W. (1980) Mammalian sperm movement in the secretions of the male and female genital tracts. In Testicular Development, Structure and Function, pp. 481-489. Eds A. Steinberger \& E. Steinberger. Raven Press, New York.

Katz, D.F., Overstreet, J.W. \& Hanson, F.W. (1980) A new quantitative test for sperm penetration in cervical mucus. Fert. Steril. 33, 179-186.

MacLeod, J. \& Gold, R.Z. (1951) The male factor in fertility and infertility. III. An analysis of motility activity in the spermatozoa of 1000 fertile and 1000 infertile men in marriage. Fert. Steril. 2, 187-195.

Makler, A., Itskovitz, J., Brandes, J.M. \& Paldi, E. (1979) Sperm velocity and percentage of motility in 100 normospermic specimens analyzed in the multiple exposure photography (MEP) method. Fert. Steril. 31, 155-161.

Nelson, C.M. \& Bunge, R.G. (1974) Semen analysis: evidence of changing parameters of male fertility potential. Fert. Steril. 75, 503-507.

Overstreet, J.W., Katz, D.F., Hanson, F.W. \& Fonseca, J.R. (1979) A simple inexpensive method for objective assessment of human sperm movement characteristics. Fert. Steril. 31, 162-172.

Perry, G., Glezerman, M. \& Insler, V. (1977) Selective filtration of abnormal spermatozoa by the cervical mucus in vitro. In The Uterine Cervix in Reproduction, pp. 118-127. Eds V. Insler \& G. Bettendorf. George Thieme Publishers, Stuttgart.

Rehan, N.E. \& Sobrero, A.J. (1975) The semen of fertile men: statistical analysis of 1300 men. Fert. Steril. 26, 492-499.

Santomauro, A.G., Sciarra, J.J. \& Varma, A.O. (1972) A clinical investigation of the role of the semen analysis and postcoital test in the evaluation of male infertility. Fert. Steril. 23, 245-251. 
Schwartz, D., Laplanche, A., Jouannet, P. \& David, G. (1979) Within-subject variability of human semen in regard to sperm count, volume and total number of spermatozoa. Importance of length of abstinence. $J$. Reprod. Fert. 57, 391-395.

Snedecor, G.W. \& Cochran, W.G. (1974) Statistical Methods, Iowa State University Press, Ames, lowa.

Sobrero, A.J. \& Rehan, N.E. (1975) The semen of fertile men. II. Semen characteristics of 100 fertile men. Fert. Steril. 26, 1048-1056.

Tredway, D.R., Fordney Settlage, D.S., Nakamura, R.M., Motoshima, M., Umezaki, C.U. \& Mishell,
D.R. (1975) Significance of timing for the postcoital evaluation of cervical mucus. Am. J. Obstet. Gynec. 121, 387-393.

van Duijn, C. Jr (1962) Velocity characteristics and numbers of bull spermatozoa in relation to ageing, determined by photo-electric methods. J. Reprod. Fert. 4, 277-290.

van Duijn, C., Jr, van Voorst, C. \& Freund, M. (1971) Movement characteristics of human spermatozoa analysed from kinemicrographs. Eur. J. Obstet. Gynec. 4, 121-135.

Received 29 September 1980

\section{Appendix}

Derivation of the equation relating the average swimming speeds of total, progressive and non-progressive spermatozoa and the percentages of progressive and non-progressive spermatozoa

Consider a population comprised of $n$ motile spermatoza. Suppose that $k$ is the number of spermatozoa that swim fast enough to be defined as 'progressive', and that $l$ is the number of spermatozoa that are defined as 'non-progressive'; then $k+l=n$. Let $\mathrm{Ps}_{i}$ be the swimming speed of the 'ith' progressive spermatozoon $(1 \leq i \leq k)$, and let $\mathrm{Ns}$, be the swimming speed of the ' $j$ th' non-progressive spermatozoon $(1 \leq j \leq l)$. By definition, the average total swimming speed, TS, is computed without distinction between progressive and non-progressive spermatozoa, i.e.

$$
\mathrm{TS}=\frac{1}{k+l}\left(\sum_{i=1}^{k} \mathrm{Ps}_{i}+\sum_{j=1}^{l} \mathrm{Ns}_{j}\right)
$$

The average swimming speed of progressive spermatozoa, PS, and the average swimming speed of non-progressive spermatozoa, NS, are defined as,

$$
\begin{aligned}
& \mathrm{PS}=\frac{1}{k} \sum_{l=1}^{k} \mathrm{Ps}_{i} \\
& \mathrm{NS}=\frac{1}{l} \sum_{j=1}^{l} \mathrm{Ns}_{l}
\end{aligned}
$$

Substituting Equations (A2) and (A3) into Equation (1), we obtain,

$$
\mathrm{TS}=\left(\frac{k}{k+l}\right) \mathrm{PS}+\left(\frac{l}{k+l}\right) \mathrm{NS}
$$

The expressions in parentheses $k /(k+l)$ and $l /(k+l)$ are simply the proportions of progressive and non-progressive spermatozoa, respectively. Therefore

$$
\begin{aligned}
\mathrm{TS} & =\left(\frac{1}{100}\right)[(\% \mathrm{P}) \mathrm{PS}+(\% \mathrm{~N}) \mathrm{NS}] \\
& =\left(\frac{1}{100}\right)[(\% \mathrm{P}) \mathrm{PS}+(1-\% \mathrm{P}) \mathrm{NS}] \\
& =\left(\frac{1}{100}\right)[(\% \mathrm{P})(\mathrm{PS}-\mathrm{NS})+\mathrm{NS}]
\end{aligned}
$$

where $\% \mathrm{P}$ and $\% \mathrm{~N}$ are respectively the percentages of progressive and non-progressive spermatozoa. 